\title{
Evaluation of Education Students with Intellectual Disability in Saudi Arabia
}

\author{
Khalid H. Alshamri ${ }^{1}$ \\ ${ }^{1}$ Jouf University, Sakaka, Saudi Arabia \\ Correspondence: Khalid H. Alshamri, Jouf University, Sakaka, Saudi Arabia. E-mail: khalshamri@ju.edu.sa
}

Received: October 5, $2018 \quad$ Accepted: November 13, $2018 \quad$ Online Published: December 30, 2018

doi:10.5539/jel.v8n1p131 URL: https://doi.org/10.5539/jel.v8n1p131

\begin{abstract}
A survey was conducted in order to evaluate the quality of education received by students with intellectual disability in Aljouf, Saudi Arabia from the perspectives of their teachers and parents. From a sample of 95 respondents, it was found that most teachers used "baby steps" strategy in delivering content for students with intellectual disabilities. Most of the parents were found to rely almost entirely on formal education for their children and were not directly involved with their children's education at home. Only a minority of the teachers were found to utilize assistive technology to augment their practice. Both teachers and parents did not feel very confident about the effectiveness of the current systems in teaching their children important social and practical skills. Recommendations based on these outcomes were provided.
\end{abstract}

Keywords: special education, intellectual disability, social skills, practical skills, Saudi Arabia

\section{Introduction}

\subsection{Introduction of Problem}

Intellectual disability is defined by the American Association of Intellectual and Developmental Disabilities (AAIDD) as a condition that imposes significant limitations in both intellectual functioning and in adaptive behavior of an individual which can impair the individual's ability to perform different everyday social and practical skills. Intellectual disabilities affect about 3\% of the general population and can range from mild to extremely debilitating (AAIDD, 2018). However, having an intellectual disability does not mean that a person is incapable of learning and developing as an individual. Rather, it means that the person has different educational needs that need to be addressed. As such, public education systems have a responsibility to provide appropriate special education services to cater to the needs of students with intellectual disabilities, and progress in this area has differed widely from one country to another.

In line with this, Saudi Arabia has been developing its special education services for more than 50 years, with more recent years being focused specifically on addressing the needs of students with intellectual disabilities (Al-Mousa, 2010; Alnahdi, 2014a). Yet the actual outcomes of these efforts have been brought into question (Alquraini, 2014; Baker, 2014; Alnahdi, 2014b), with a dearth of studies formally investigating the impact on students as perceived by their teachers and parents or guardians. As such, this study conducts an evaluation of special education in Saudi Arabia from the perspectives of these stakeholders.

\subsection{Objectives of the Study}

Specifically, this study addresses three objectives. First, it seeks to describe the distribution of teaching strategies employed by public school teachers for students with intellectual disabilities in Aljouf, Saudi Arabia. Next, it seeks to determine the extent to which such teachers are using assistive technology in their classrooms. Third, it seeks to examine the perspectives of teachers and parents in relation to the adequacy of the school curriculum on the needs of students with intellectual disabilities, and the extent to which parents rely on it to address their children's special education needs.

\section{Review of Related Literature}

\subsection{Factors that Affect Achievement of Students with Intellectual Disabilities}

Many factors have been found to affect achievement in general of children with MID. Common among different studies is the presence of sufficient, accessible support for the child and the child's parents (Teather \& Hillman, 
2017; Goodey, 2015; Alquraini, 2011). As explained by Goodey (2015), intellectual disability in itself is not debilitating to the development of a child for so long as those taking care of the child are accurately away of his or her condition and how to nurture the child properly given this condition. This coincides with input about intellectual disabilities from Tassé (2013) in the DSM-5, which consider individuals belonging in this category as absolutely capable of achieving high functioning status and being significant contributors to society. However, as also pointed out by Goodey (2015), However, as also pointed out by Goodey (2015), it is precisely the lack of sufficient support that stops children with the intellectual disability from achieving their full potential.This lack of sufficient support is typically due to the incorrect mindset about what a person with intellectual disabilities can accomplish.

\subsection{Structural Developments in Saudi Arabian Special Education}

The Ministry of Education formally began to address special education needs in Saudi Arabia during the 1960's, primarily targeting students who were visually impaired (Al-Mousa, 2010). The focus of special education in the country has since grown extensively, with the establishment of a General Directorate for Special Education (DGSE) in 1974 that studied the different needs of students with disabilities and developed policies in order to address these needs (Al-Mousa, 2010). During the 1990's, the Ministry of Education implemented inclusive education protocols in public schools, mandating the integration of students with disabilities with the mainstream student population (Alnahdi, 2014a). Alongside this, special education classes were established within mainstream schools as a means of assisting students with disabilities with disability-specific learning needs (Alnahdi, 2014a). In particular, these programs covered students with visual or hearing impairments, autism, or intellectual disabilities, with $62 \%$ of the programs aimed for students with intellectual disabilities (Alnahdi, 2014a). As such, in the current setting, two types of educational placements for students with intellectual disability are available in the country. While students with intellectual disabilities generally enter the mainstream educational system, those with severe disabilities have the option of entering specialized institutions that cater specifically to students with intellectual disabilities (Al-Mousa, 2010). These inputs show that considerable development has been made in the structure of special education in Saudi Arabia. Different services and facilities exist in order to cater to the educational needs of students across different levels of intellectual disability.

\subsection{Quality of Saudi Arabian Special Education}

Despite the developed structure of special education services in the country, various authors have raised questions of the current quality of special education in Saudi Arabia. While Al-Mousa (2010) characterized special education in Saudi Arabia as a success, Alquraini (2014) discussed that the large amount of resources, time, and effort expended by the government in this endeavor has yet to yield evidence of optimal outcomes. While there have been facilities and programs set in place in order to address the educational needs of students with intellectual disabilities, little research has been conducted to examine different aspects of efficacy of these measures (Alquraini, 2014). Baker (2014) likewise pointed out the lack of impact studies to validate current programs that have already been running for a considerable amount of time, and posited a cultural rationale behind the absence of such studies. As a culture with very high power-distance index based of Hofstede's cultural dimensions, it is less likely for the efficacy of government led programs to be challenged. This is evidenced by studies such as Al-Zoubi and Rahman (2013), which was supposed to evaluate special education programs in Saudi Arabian universities but did so only from the perspectives of the heads of such programs. In contrast to this, another study by Alnahdi (2014b) which examined one aspect of special education quality from the perspective of teachers found that special education teachers actually had a negative perception about their efficacy in providing transitionary services to their students. That is, the teachers in the study felt that they were not sufficiently equipped to prepare special education students for life outside the school (Alnahdi, 2014b). This underscores the importance of examining other aspects of special education quality in the country from the perspectives of stakeholders such as teachers and the students' parents, which is the gap in literature that is addressed in this study.

\section{Methodology}

This study employed a quantitative, descriptive design that administered a survey instrument to a sample of teachers and parents with children who have intellectual disabilities at nine different public schools in Aljouf, Saudi Arabia. Potential respondents among the parents were identified through the school under appropriate ethics regulations as mandated by the public school system. Surveys were deployed for a period of four weeks and all of the parents and teachers who accomplished and returned the forms composed the sample of the study. Out of 110 questionnaires deployed, 95 were successfully completed, yielding a response rate of $86 \%$.

The survey instrument was constructed for this study and is divided into three sections. The first section collects 
some demographic and professional characteristics of the respondents. Particularly, the respondent's gender, age, educational attainment, and relationship with the students (teacher or parent) were of interest. The second section was to be accomplished only by the teachers, and asked about the teachers' perspectives of the different facets of quality of education that is experienced by students with intellectual disabilities at their school as well as their own style and readiness in teaching such students. The third section was to be accomplished only by the parents, and asked about their perspective of quality in the education that their child receives from the school, as well as their own involvement in their child's education.

Data collected from the survey were tabulated and analysis was conducted to determine $95 \%$ confidence intervals for the responses. Descriptive contingency tables were constructed in order to capture the demographic distribution of the sample, as well as different variables of interest such as the amount of time that teachers spent with students and the range of strategies that they used to address the needs of students with intellectual disabilities. Analysis was conducted to enable the determination of the range of values between which specific parameters of interest were considered to be located. In particular, estimating the mean response to the extent to which the school curriculum is relevant for the growth, confidence, and skillfulness of the children was of interest. Relevant tests were conducted to compare the responses of teachers and parents on specific common questions at a $5 \%$ level of significance.

\section{Results}

Out of the 95 questionnaires that were successfully accomplished and returned, 47 where from teachers and 48 were from parents, showing that both stakeholders were sufficiently represented. Tables 1 to 4 describe different demographic characteristics of the sample.

Table 1 shows that both males and females were represented among teachers and parents. Among teachers, 51\% were males while among parents, $64 \%$ were males. In terms of marital status, Table 2 shows that a majority of both parents and teachers in the sample were married, with $72 \%$ among teachers and $65 \%$ among parents. This implies that about $35 \%$ of the children in the study were being raised by only one of their parents.

Table 1. Distribution of respondents by gender

\begin{tabular}{lll}
\hline & Frequency & \\
\hline & MALE & FEMALE \\
Teachers & 24 & 23 \\
Parents & 31 & 17 \\
Total & 55 & 40 \\
\hline
\end{tabular}

Table 2. Distribution of respondents by marital status

\begin{tabular}{lll}
\hline & Frequency & \\
\hline & SINGLE & MARRIED \\
Teachers & 13 & 34 \\
Parents & 17 & 31 \\
Total & 30 & 65 \\
\hline
\end{tabular}

Table 3 shows the age distribution of the sample. For both the teachers and the parents, a majority were found to be between 30 to 39 years old. This implies that teachers and parents who responded to the study at least have similar age distributions, such that age is not expected to be a factor in considering any differences between their perspectives.

Table 3. Distribution of respondents by age

\begin{tabular}{lllll}
\hline & Frequency & & & \\
\hline & $20-29$ & $30-39$ & $40-49$ & 9 \\
50 -above & 2 \\
Teachers & 7 & 29 & 11 & 3 \\
Parents & 8 & 26 & 20 & 5 \\
Total & 15 & 55 & & 5 \\
\hline
\end{tabular}


Finally, Table 4 shows that a majority of both teachers and parents, $85 \%$ and $83 \%$ respectively, have at least a college degree. As such, they are similar in terms of their educational attainment, which means that this factor is not likely to play a role in differentiating between their perspectives on the variable of interest in the study.

Table 4. Distribution of respondents by educational qualification

\begin{tabular}{llll}
\hline & Frequency & & \\
\hline & Secondary & College & Masters Degree \\
Teachers & 7 & 34 & 6 \\
Parents & 8 & 31 & 9 \\
Total & 15 & 65 & 15 \\
\hline
\end{tabular}

Overall, the results from Tables 1 to 4 substantiate that the sample collected from two groups of stakeholders that were of interest in this study are comparable in terms of different demographic characteristics, which is a significant observation in relation to controlling for the effect of such characteristics on any differences that can be observed between the two groups.

With regard to the teachers' perspectives on education for students with intellectual disabilities in their classes, $82 \%$ claimed to spend more than 4 hours with such students on a daily basis, while the rest claimed to spend between 2 to 4 hours focused on them shown in Table 5. This implies that all of the teachers recognize the need to spend more time with children that have intellectual disabilities as these students require their greater attention in order for them to be able to keep up with the rest of the class.

Table 5. Amount of time teachers spend with students daily

\begin{tabular}{lllllll}
\hline & Frequency & \multicolumn{5}{c}{ Percentage } \\
\hline & $<$ hours & $2-4$ hours & $>4$ hours & $<2$ hours & $2-4$ hours & $>4$ hours \\
Teachers & -- & 8 & 39 & -- & $16.8 \%$ & $82.2 \%$ \\
Total & -- & 8 & 39 & -- & $16.8 \%$ & $82.2 \%$ \\
& $\mathbf{4 7}$ & & & $\mathbf{1 0 0} \%$ & & \\
\hline
\end{tabular}

The strategies that teachers use in addressing the needs of students with intellectual disabilities are shown in Table 6. Table 6 shows that a majority of the teachers used "baby steps" as their preferred strategy, which is a cognitive technique in which a series of scaffolds are used in order to guide the student towards achieving a desired outcome. The learning outcome is subdivided into several steps, enabling the student to focus on each small step without needing to worry about the final outcome. Other popular strategies that were identified were group learning and play-based learning. This shows that teachers generally employ different strategies to address the learning needs of students with intellectual disabilities. While some strategies are more popular than others, each has its own advantages and disadvantages, and so some teachers opt to use multiple strategies in their practice.

Table 6. Teaching strategies used

\begin{tabular}{llllll}
\hline Teachers & & & & & \\
\hline & Hands on & Play Based & Baby Steps & Group Learning & All of the Above \\
Frequency & 10 & 5 & 17 & 8 & 7 \\
Percentage & $21 \%$ & $10.6 \%$ & $36.8 \%$ & $16.8 \%$ & $14.6 \%$ \\
\hline
\end{tabular}

All the teachers reported that they were either familiar or very familiar with the strategies that they used. Likewise, all of the teachers reported that the current curriculum that they were using was updated. The teachers generally believe that the response of their students on their teaching is positive. About $88 \%$ of teachers reported that students responded effectively to their teaching. However, only $32 \%$ of the teachers reported using assistive technology. Among these, the types of assistive technology that were identified included memory aids and educational software. About $76 \%$ of parents reported relying on what is being taught at school for their child's education, with the rest reporting spending a little time after school to teach their children. Of those who said 
they spent a little time, 8 claimed to use materials from the internet, while 3 claimed to develop materials themselves. Of those who spent time teaching their children at home, 4 claimed that their child's response was slightly effective, 6 claimed it was effective, while 1 claimed it was very effective.

Finally, with regard to the relevance of what is being taught in school in terms of growth, confidence, and skillfulness of the children, teachers were found to have a mean response of 3.7 with a confidence interval of 3.2 to 4.3 while parents were found to have a mean response of 3.4 with a confidence interval of 3.1 to 3.7 . This indicates that at a 0.05 significance level, there is no evidence that teachers and parents differ in terms of their opinion about the relevance of content taught in school on growth, confidence, and skillfulness of children with intellectual disabilities.

\section{Discussion}

Results from the survey highlight the importance of having effective special education in Saudi Arabian schools, particularly in relation to developing students with intellectual disabilities on social and practical skills. As found from the survey, a large majority of parents spend little to no time augmenting the formal education received by their children. This is problematic since external support, particularly from the child's parents, has been identified as one of the critical elements for the success of special education (Ng et al., 2015; Stoner, 2015). The parents of children with intellectual disabilities need to play a strong role in their children's education, but it is the responsibility of the school system and its teachers to properly orient and guide parents towards being able to assume this role effectively (Stoner, 2015). In the Saudi Arabian setting, no evidence of such support from the existing school system was found, which corroborates criticisms raised by Alquraini (2014) on the direction in which special education development in Saudi Arabia is taking despite utilizing considerable resources. This is further supported by the result that only a minority of teachers in the survey used any form of assistive technology to augment their teaching. Assistive technologies for students with intellectual disabilities have been known to be useful for at least the last decade (Bakken \& Wojcik, 2005), with more recent works reemphasizing its role in effective special education (Bouck \& Flanagan, 2014; Papanastasiou et al., 2017). This finding implied some resistance from teachers in terms of integrating new technologies in their established teaching procedures, a phenomenon that was also found by Arar and Abramovitz (2017) in investigating technology assimilation in an Arabic school in the overseas schools. Arar and Abramovitz (2017) found that resistance to change among the teachers was anchored on their reservations about the actual effectiveness of new technologies relative to the effort needed to change the way they teach in order to incorporate the use of such technologies. This problem was also one of the elements identified by Alnahdi (2014b) particularly in the Saudi Arabian school setting. As in the other studies, Alnahdi (2014b) cited insufficient integration of technology as one of the hindrances that kept teachers from being able to better address practical educational needs of students with intellectual disabilities.

The result comparing the perceptions of teachers and parents about how well the current educational system prepares their children for practical and social engagements outside of school indicate that both groups only have an undecided to moderately positive belief that the current system does achieve this goal. This is reasonable when considering the implications of the other results that were discussed. Consistent with Alnahdi (2014b) and Al-Mousa (2010), it is evident that special education in Saudi Arabia still requires considerable development in order for it to be able to effectively address the educational needs of students with intellectual disabilities.

\section{Conclusion and Recommendations}

This study was able to show that both teachers and parents of children with intellectual disabilities recognize the insufficiency of the existing special education system in Saudi Arabia in providing effective education to children with intellectual disabilities, specifically towards helping such children develop effective social and practical skills. The study was also able to identify a number of key development points that can be addressed by the Ministry of Education in line with this finding.

First, it is important to sufficiently involve parents in the education of their children. Parents or guardians of children with intellectual disabilities are an invaluable support system for such children's education. One direction that can be taken towards realizing this goal is training teachers towards interacting with and orienting parents about their role in their children's education. Teachers must take the first step in connecting with parents and explaining their importance to their child's social and practical skills learning. By successfully engaging parents in this way, teachers can effectively influence them to become more involved. At the same time, teachers, through proper prior training, can provide parents with direct guidance on what they can do to support their child's education.

Second, the Ministry of Education should direct more resources towards training teachers in the use of assistive 
technology specifically for addressing educational needs of students with intellectual disabilities. Such targeted training is what is needed in order for teachers to realize the importance of assistive technology in special education. This training should not just include skills development, but also appreciation and motivation of teachers to actually apply the skills that they learn in their practice. In doing so, such training can build the confidence and belief of teachers that using such technologies will lead to better educational outcomes.

\section{References}

AAIDD. (2018). Definition of Intellectual Disability. Retrieved February 26, 2018, from http://aaidd.org/intellectual-disability/definition\#.WpWgD1rwbDc

Al-Mousa, N. (2010). The experience of the Kingdom of Saudi Arabia in mainstreaming students with special educational needs in public schools: A success story. The Arab Bureau of Education for the Gulf States, Riyadh, Saudi Arabia.

Alnahdi, G. (2014a). Special Education Programs for Students with Intellectual Disability in Saudi Arabia: Issues and Recommendations. The Journal of the International Association of Special Education, 15(1), $183-91$

Alnahdi, G. (2014b). Special education teacher transition-related competencies and preparation in Saudi Arabia. International Journal of Special Education, 29(2), 1-9.

Alquraini, T. (2014). Special Education Today in the Kingdom of Saudi Arabia. In A. F. Rotatori, J. P. Bakken, S. Burkhardt, F. E. Obiakor, \& U. Sharma (Eds.), Special Education International Perspectives: Biopsychosocial, Cultural, and Disability Aspects (pp. 505-528). Emerald Group Publishing Limited. https://doi.org/10.1108/S0270-401320140000028023

Al-Zoubi, S., \& Rahman, M. (2013). An evaluation of special education program in Saudi Universities according to national standards. International Journal of Asian Social Science, 3(8), 1694-1703.

Arar, K., \& Abramovitz, R. (2017). Teacher-related factors in assimilation of technological change in schools: The case of an Arab school in Israel. International Journal of Educational Management, 31(6), 766-779. https://doi.org/10.1108/IJEM-03-2016-0057

Baker, F. (2014). Inclusive Education in the Middle East. Education, Business and Society: Contemporary Middle Eastern Issues, 7(1), 75-78.

Bakken, J., \& Wojcik, B. (2005). Technology Resources for Persons with Learning Disabilities. In S. Burkhardt, F. Obiakor, \& A. F. Rotatori (Eds.), Current Perspectives on Learning Disabilities (pp. 113-132). Emerald Group Publishing Limited.

Bouck, E., \& Flanagan, S. (2014). Technological Advances in Special Education. In A. F. Rotatori, J. P. Bakken, S. Burkhardt, F. E. Obiakor, \& U. Sharma (Eds.), Special Education International Perspectives: Biopsychosocial, Cultural, and Disability Aspects (pp. 209-235). Emerald Group Publishing Limited. https://doi.org/10.1108/S0270-401320140000027007

Goodey, C. (2015). Why study the history of learning disability? Tizard Learning Disability Review, 20(1), 3-10. https://doi.org/10.1108/TLDR-04-2014-0011

Ng, S., Hoi, T., \& Lee, T. (2015). How parents were involved in a special school in Hong Kong. International Journal of Educational Management, 29(4), 420-430. https://doi.org/10.1108/IJEM-07-2014-0095

Papanastasiou, G., Drigas, A., Skianis, C., \& Lytras, M. (2017). Serious games in K-12 education: Benefits and impacts on students with attention, memory and developmental disabilities. Program, 51(4), 424-440. https://doi.org/10.1108/PROG-02-2016-0020

Stoner, J. (2015). Roles of Parents/Families/Guardians. In J. P. Bakken \& F. E. Obiakor (Eds.), Interdisciplinary Connections to Special Education: Important Aspects to Consider (pp. 131-150). Emerald Group Publishing Limited. https://doi.org/10.1108/S0270-40132015000030A006

Tassé, M. (2013) Diagnostic Criteria for Intellectual Intellectual Disability. Retrieved November 4, 2018, from https://adayinourshoes.com/wp-content/uploads/2015/05/dsm5-idd-diagnostic-criteria.pdf

Teather, S., \& Hillman, W. (2017). The invisible students with disabilities in the Australian education system. Equality, Diversity and Inclusion: An International Journal, 36(6), 551-565. https://doi.org/10.1108/EDI-02-2017-0029 


\section{Copyrights}

Copyright for this article is retained by the author, with first publication rights granted to the journal.

This is an open-access article distributed under the terms and conditions of the Creative Commons Attribution license (http://creativecommons.org/licenses/by/4.0/). 